\begin{tabular}{|ll|}
\hline Received & $:$ 30 September 2019 \\
Revised & $:$ 1 Oktober 2019 \\
Accepted & $:$ 22 Oktober 2019 \\
Online & $:$ 25 Oktober 2019 \\
Published & $:$ 29 Oktober 2019 \\
\hline
\end{tabular}

\title{
RELIGIOUS MATH CHARACTER SEBAGAI SOLUSI UNTUK MENINGKATKAN KUALITAS PEMBELAJARAN MATEMATIKA DAN KARAKTER PELAJAR DI INDONESIA
}

\author{
Rahma Rosaliana Saraswati ${ }^{1, \text { a) }}$, Hidayat ${ }^{2)}$ \\ ${ }^{1}$ Matematika, Fakultas MIPA, Universitas Negeri Jakarta \\ 2 Teknis Mesin, Fakultas Teknik, Universitas Negeri Jakarta \\ Email : ${ }^{\text {a) }}$ rahma.rosaliana@gmail.com
}

\begin{abstract}
Quality education is one of the factors that contribute to the development of a country and is one of 17 Sustainable Development Goals (SDGs) targets. Mathematics is one of the subjects taught in Indonesian schools. Based on data from the Program for International Student Assessment (PISA) in 2012 stated that the mathematical ability of 15-year-old students in Indonesia ranked 63 out of 64 countries with an average score of 375 . This shows that, the quality of mathematics education in Indonesia is still low. Not only the quality of mathematics education in Indonesia. The emotional intelligence of students in Indonesia is also still low. This is evidenced by the rise of millennial problems such as free sex, drugs, and other juvenile delinquency. For example, in the Ngajuk area, from the 2018 PPA Unit data there were 55 cases of juvenile delinquency and in 2017 only 36 cases, up nearly 50\%. In addition, based on KPAI data, student brawls in Indonesia in 2018 increased by around $1.1 \%$ compared to 2017 . Based on the above statement, it is necessary to find the right solution to improve the quality of mathematics learning and the character of students in Indonesia. The solution is the religious math character. Religious math character is a strategy to teach mathematics by instilling religious values in its learning. In its implementation, this mathematics learning uses the meaning learning model. Based on the results of the literature review, the use of mathematics learning strategies based on religious math characters is able to improve mathematics learning outcomes as well as moral ethics of students through meaningful learning steps. Through this strategy mathematics learning is more meaningful because it links concepts not memorization, so that it can improve the quality of mathematics learning as well as the character of students in Indonesia.
\end{abstract}

Keyword: Character, Math, Religion.

\begin{abstract}
Abstrak
Pendidikan yang berkualitas adalah salah satu faktor yang berkontribusi terhadap pembangunan suatu negara dan merupakan salah satu dari 17 sasaran Sustainable Developmet Goals (SDGs). Matematika adalah salah satu mata pelajaran yang diajarkan di sekolah Indonesia. Berdasarkan data dari Program for International Student Assessment (PISA) pada tahun 2012 menyatakan bahwa kemampuan matematika siswa berusia 15 tahun di Indonesia berada di peringkat 63 dari 64 negara dengan skor rata - rata 375. Hal ini menunjukan bahwa, masih rendahya kualitas pendidikan matematika di Indonesia.Tidak hanya kualitas pendidikan matematika di Indonesia. Kecerdasan emosional peserta didik di Indonesia juga masih rendah. Hal ini dibuktikan dengan maraknya masalah - masalah millenial seperti, seks bebas, narkoba, dan kenakalan remaja lainnya. Contohnya, di daerah Ngajuk, dari data Unit PPA tahun 2018 tercatat ada 55 kasus kenakalan remaja dan tahun 2017 hanya 36 kasus atau naik hampir 50\%. Selain itu, berdasarkan data KPAI tawuran pelajar di Indonesia pada tahun 2018
\end{abstract}


meningkat sekitar 1,1\% dibandingkan tahun 2017. Berdasarkan pernyataan di atas, maka diperlukan solusi yang tepat guna meningkatkan kualitas pembelajaran matematika dan karakter peserta didik di Indonesia. Solusi tersebut adalah religious math character. Religious math character merupakan sebuah strategi membelajarkan matematika dengan menanamkan nilai-nilai agama dalam pembelajarannya. Dalam pelaksanaannya, pembelajaran matematika ini menggunakan model pembelajaran pemaknaan. Bedasarkan hasil kajian pustaka, penggunaan strategi pembelajaran matematika berbasis religious math character ini mampu meningkatkan hasil belajar matematika sekaligus etika moral peserta didik melalui langkah - langkah pembelajaran bermakna. Melalui strategi ini pembelajaran matematika lebih bermakna karena mengaitkan konsep bukan hafalan, sehingga dapat meningkatkan kualitas pembelajaran matematika sekaligus karakter peserta didik di Indonesia.

\section{Kata Kunci: Karakter, Matematika, Religion.}

\section{PENDAHULUAN}

Pendidikan yang berkualitas adalah salah satu faktor yang berkontribusi terhadap pembangunan suatu negara dan merupakan salah satu dari 17 sasaran Sustainable Developmet Goals (SDGs) yang bertujuan untuk memastikan agar semua orang mendapatkan akses pendidikan berkualitas dan kesempatan belajar sepanjang hayat. Pendidikan adalah usaha sadar dan terencana untuk mewujudkan suasana belajar dan proses pembelajaran agar peserta didik secara aktif mengembangkan potensi dirinya untuk memiliki kekuatan spiritual keagamaan, pengendalian diri, kepribadian, kecerdasan, akhlak mulia serta ketrampilan yang diperlukan dirinya, masyarakat, bangsa dan negara (UU Nomor 20 Tahun 2003). Maka berdasarkan pengertian tersebut, tujuan sebenarnya dari pendidikan bukan hanya tercapainya kecerdasan intelektual, tetapi juga tercapainya kecerdasan emosional yang tinggi berupa moral dan adab yang baik pada anak sebagai seorang peserta didik.

Hasil penelitian dari Harvard University, menunjukkan bahwa keberhasilan seseorang yang selama ini ditentukan oleh faktor intelektualitas adalah pandangan yang ternyata keliru. Faktor intelektual hanya memberikan kontribusi $20 \%$ pada kesuksesan seseorang, kontribusi kecakapan emosi justru mencapai 80\%. (Goleman,2001)

Matematika adalah salah satu mata pelajaran yang diajarkan di sekolah Indonesia. Berdasarkan data dari Program for International Student Assessment (PISA) pada tahun 2012 menyatakan bahwa kemampuan matematika siswa berusia 15 tahun di Indonesia berada di peringkat 63 dari 64 negara dengan skor rata - rata 375 . Hal ini menunjukan bahwa, masih rendahya kualitas pendidikan matematika di Indonesia.

Tidak hanya kualitas pendidikan matematika di Indonesia. Kecerdasan emosional peserta didik di Indonesia juga masih rendah. Hal ini dibuktikan dengan maraknya masalah - masalah millenial seperti, seks bebas, narkoba, dan kenakalan remaja lainnya. Contohnya, di daerah Ngajuk, dari data Unit PPA tahun 2018 tercatat ada 55 kasus kenakalan remaja dan tahun 2017 hanya 36 kasus atau naik hampir $50 \%$. Dari 55 kasus tersebut dengan rincian penganiayaan 8 kasus, pengeroyokan 15 kasus, pencurian 13 kasus, persetubuhan 18 kasus dan perjudian 1 kasus (Harianto, 2018). Selain itu, berdasarkan data KPAI tawuran pelajar di Indonesia pada tahun 2018 meningkat sekitar 1,1\% dibandingkan tahun 2017 (Firmansyah, 2018).

\section{METODE PENELITIAN}

Metode penulisan karya tulis ilmiah ini adalah studi literatur. Data-data yang digunakan penulis bersumber dari literatur yang relevan dengan kasus permasalahan. Beberapa diantaranya bersumber dari buku referensi, jurnal, dan abstrak hasil penelitian. Menurut Sarwono (2006:49) beberapa sumber kepustakaan yang dapat digunakan oleh peneliti yaitu abstrak hasil peneltian, indeks, review, jurnal, buku referensi. Data yang telah diperoleh dari studi literatur kemudian dipilih sesuai kebutuhan guna menyelesaikan permasalahan yang ada. Pengolahan data ini dilakukan dengan mengaitkan data - data 
yang ada dengan objek gagasan sehingga diperoleh konsep gagasan yang bisa memecahkan permasalahan. Sedangkan, analisis data dalam karya tulis ilmiah ini dilakukan secara deskriptif.

\section{HASIL DAN PEMBAHASAN}

\section{Analisis Implementasi Religious Math Character}

Strategi pendidikan bergantung kepada sistem pendidikan, akan tetapi sistem pendidikan tidak hanya mengatur tujuan pembelajaran dan metode yang digunakan, tetapi di dalamnya juga mengatur segala hal yang mendukung berjalannya pembelajaran. Sistem pendidikan yang lengkap membutuhkan peran kolaboratif dari berbagai sektor, diantaranya adalah pemerintah sebagai regulator, akademisi di bidang agama dan matematika sebagai konseptor berbasis keilmuan dan lahirnya ide-ide kreatif, sekolah sebagai esekutor dan juga orang tua peserta didik sebagai kontroller. Peran kolaboratif tersebut tentunya tidak terbentuk instan, namun memerlukan proses yang konsisten dan sistematis, mulai dari sosialisasi, persuasi, hingga implementasi.

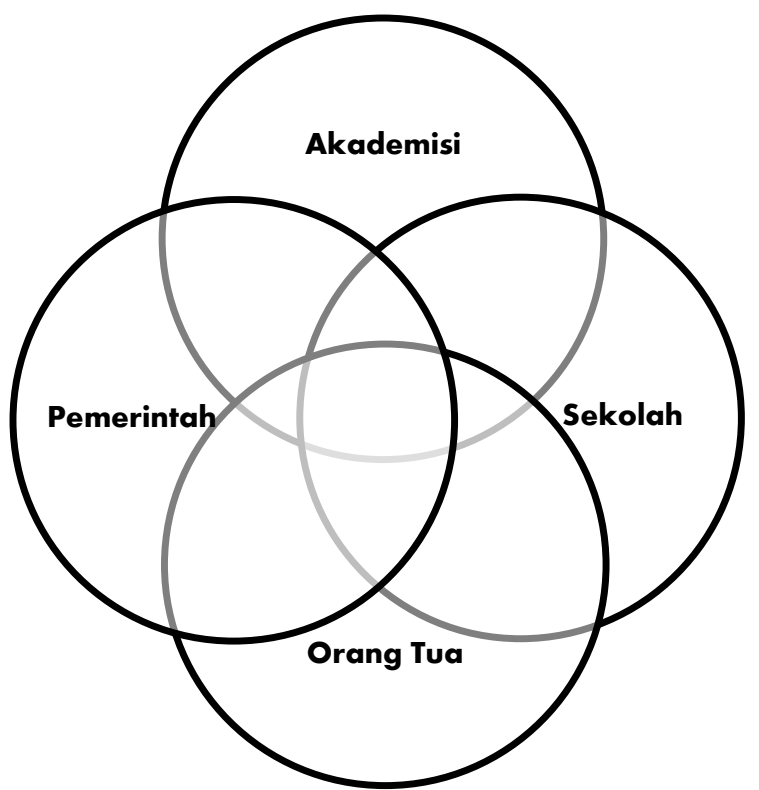

Gambar 1. Diagram Kolaboratif

Implementasi religious math character dapat digunakan pada seluruh materi pembelajaran matematika. Salah satunya dalam pembelajaran aritmatika sosial mengenai bunga. Bunga adalah jasa dari pinjaman atau simpanan yang dibayarkan pada akhir jangka waktu yang telah disepakati bersama. Contoh soal dari materi ini adalah "Bismo menabung di bank A dengan suku bunga tunggal $2 \%$ perbulan. Setelah 10 bulan tabungannya menjadi 30 juta rupiah. Uang yang ditabung Bismo adalah?"

Berdasarkan buku "Bank Syariah : dari Teori ke Praktik" karya M. Syafi'i Antonio menyatakan bahwa, orang-orang yahudi dilarang mempraktekkan pengambilan bunga. Pelarangan ini banyak terdapat dalam kitab suci mereka, baik dalam Old Testament (Perjanjian Lama) maupun undangundang Talmud. Praktik pengambilan bunga juga dicela oleh para ahli filsafat.

Dua orang ahli filsafat Yunani terkemuka, Plato (427 - 347 SM) dan Aristoteles (384 - 322 SM), mengecam praktik bunga. Begitu juga dengan Cato (234 - 149 SM) dan Cicero (106 - 43 SM). Para ahli filsafat tersebut mengutuk orang-orang Romawi yang mempraktekkan pengambilan bunga. Dalam islam larangan praktik ini tertuang dalam Al - Qur'an surat Al- Baqarah ayat 278 - 279. Sedangkan dalam agama kristen, konsep bunga masih menjadi perdebatan di kalangan tokoh kristen.

Berdasarkan pernyataan tersebut, dapat disimpulkan bahwa seluruh agama melarang transaksi yang ada bunga di dalamnya, maka strategi yang dapat dilakukan yaitu dengan mengubah tujuan 
pembelajaran materi mengenai bunga, bukan menghitung bunga demi keuntungan semata saja tetapi agar tidak tejerumus ke dalam dosa. Oleh sebab itu, contoh soal di atas harus diubah, sesuai dengan tujuan tersebut yaitu menjadi, "Bismo menabung di bank A dengan suku bunga tunggal 2\% perbulan. Setelah 10 bulan tabungannya menjadi 30 juta rupiah. Uang yang harus dikembalikan Bismo kepada bank agar terhindar dari dosa riba adalah?".

Religious math character juga dapat diterapkan pada materi relasi dan fungsi, dimana dalam mempelajari materi ini peserta didik dikaitkan dengan nilai agama yang mengajarkan bagaimana seharusnya berelasi atau berinteraksi dengan orang lainnya khususnya dengan lawan jenis. Agar tidak terjadi pergaulan bebas yang dilakukan oleh peserta didik. Selain itu, masih banyak lagi materi dalam pembelajaran matematika yang dapat diperbaiki dengan strategi pembelajaran religious math character.

\section{Sintesis Strategi Pembelajaran Religious Math Character}

Strategi pembelajaran adalah pola tindakan pengajaran yang berfungsi untuk mencapai tujuan pembelajaran tertentu (Kisyani Laksono, dkk., 2016). Strategi pembelajaran juga dapat disebut sebagai model pembelajaran. Untuk membelajarkan siswa sesuai dengan cara gaya belajar mereka sehingga tujuan pembelajaran dapat dicapai dengan optimal ada berbagai model pembelajaran. Dalam prakteknya, guru harus ingat bahwa tidak ada model pembelajaran yang paling tepat untuk segala situasi dan kondisi.

Oleh karena itu, dalam memilih model pembelajaran yang tepat haruslah memperhatikan kondisi siswa, sifat materi bahan ajar, dan fasilitas-media yang tersedia, serta kondisi guru itu sendiri (Erman, 2008)

Keterpisahan antara agama dan ilmu terjadi karena pandangan agamawan, perspektif ilmuwan, dan penglihatan masyarakat yang tidak menemukan pertemuan keduanya, atau yang mempertentangkannya, namun sekarang, pandangan, perspektif, dan penglihatan mereka, sudah mulai mereka koreksi sendiri. Dari sini, maka pertemuan antara agama dan ilmu itu yang tepat bukanlah integrasi, tetapi [re]integrasi atau [re] unifikasi, karena sejak semula atau pada realitasnya sebenarnya memang sudah menyatu atau bersatupadu, tetapi perspektif manusia lah yang memisahkannya, bahkan mempertentangkannya (Muslih, 2016).

Melalui petunjuk agama pengembangan ilmu dilakukan untuk membongkar misteri ilmiah, untuk kemaslahatan kehidupan manusia. Hal ini bukan soal merespons tantangan ilmu sekuler, tetapi soal menawarkan kemanfaatan yang seluas-luasnya bagi keilmuan, sosial, dan kemanusiaan. Dengan begitu, pengembangan ilmu berbasis agama itu juga bukan proyek ideologis, tetapi proyek ilmiah yang bernilai agama (Muslih, 2016).

Bedasarkan hasil kajian pustaka, penggunaan strategi pembelajaran matematika berbasis religious math character ini mampu meningkatkan hasil belajar matematika sekaligus etika moral peserta didik melalui langkah - langkah pembelajaran bermakna yaitu, mengorientasikan peserta didik pada masalah atau pertanyaan, merancang proses pemecahan masalah atau menjawab pertanyaan, membimbing penyelidikan, mengkomunikasikan hasil, negosiasi dan konfirmasi, pemaknaan, evaluasi dan refleksi. Melalui strategi ini pembelajaran matematika lebih bermakna karena mengaitkan konsep bukan hafalan, sehingga dapat meningkatkan kualitas pembelajaran matematika di Indonesia sekaligus karakter peserta didik di Indonesia. 


\section{KESIMPULAN}

Berdasarkan analisis dan sintesis yang mengacu pada penelitian relevan, melalui langkah-langkah strategi proses pembelajaran pemaknaan, yaitu pembelajaran matematika dengan berbasis religious math character, merupakan sebuah strategi membelajarkan matematika dengan menanamkan nilainilai agama dalam pembelajarannya yang diharapkan dapat membuat peserta didik berpikir secara sistematis, terlatih untuk memahami sendiri dan menggunakan penalaran mereka dalam menyelesaikan soal-soal matematika berkaitan dengan merepresentasikan dan memvisualisaikan hubungan konseptual dengan abstrak. Selain itu, strategi ini juga dapat mengajarkan peserta didik mengenai nilai - nilai agama. Hal ini tentunya dapat menjadi solusi cerdas yang bersifat komprehensif, sehingga dapat membantu pemerintah dalam meningkatkan kualitas pembelajaran matematika dan karakter peserta didik. Sehingga, dapat berdampak pada kualitas pendidikan Indonesia sesuai dengan salah satu target yang terdapat pada tujuan pembangunan berkelanjutan atau Sustainable Development Goals (SDGs).

\section{REFERENSI}

A. A. (1998). Rekonstruksi Kritis Ilmu dan Pendidikan Islam, dalam Abdul Munir Mulkhan, dkk., Religiusitas Iptek. Yogyakarta: Pustaka Pelajar.

Adjie, Nahrowi dan Maulana. (2006). Pemecahan Masalah Matematika. Ed.I. Cet.I. Bandung: UPI PRESS.

Astuti, M. P. (2011). Hubungan Antara Fanatisme Terhadap Tokoh Idola dengan Imitasi pada Remaja. Skripsi thesis, Universitas Muhammadiyah Surakarta.

Baharudin. (2011). Dikotomi Pendidikan Islam. Bandung: Remaja Rosydakarya.

Daulay, H. P. (2004). Pendidkan Islam dalam Sistem Pendidikan Nasional di Indonesiai. Jakarta: Kencana.

Firmansyah, M. J. (2018, September 12). KPAI: Tawuran Pelajar 2018 Lebih Tinggi Dibanding Tahun Lalu. Retrieved September 25, 2018, from Tempo.Co: https://metro.tempo.co/read/1125876/kpaitawuran-pelajar-2018-lebih-tinggi-dibanding-tahun-lalu

Goleman Daniel, 2001. Working With Emotional Intelegence :Kecerdasan Emosi Untuk Mencapai Prestasi Puncak. Jakarta : PT Gramedia Pustaka Utama.

Jauhari. (2014). Nafkah dalam Perspektif Al - Qur'an. Tesis, UIN Sunan Ampel Surabaya.

Karim, M. B., Asyhar, A. H., \& Nisa, T. F. (2016). Implementasi Islamic Math Character : Paradigma Baru Dalam Pembelajaran Matematika. Jurnal Review Pembelajaran Matematika, 57 - 60.

M. Nisfiannor, R. T. (2004). Hubungan Antara Komitmen Beragama dan Subjective Well-Being Pada Remaja Akhir. Jurnal Psikologi Vol. 2 No. 1, 74 - 93.

Mawarsih, S. E., Susilaningsih, \& Hamidi, N. (2013). Pengaruh Perhatian Orang Tua dan Motivasi Belajar terhadap. JUPE UNS, 1(3): 1 - 13 .

Mayasari, R. (2014). Religiusitas Islam dan Kebahagiaan (Sebuah Telaah dengan Perspektif Psikologi). Al - Munzir 7(2): 81 - 100.

Muslih, M. (2016). Al - Qur'an dan Lahirnya Sainsteistik. Tsaqofah, 12(2): 257 -280. 
Nata, A. (2014). Perspektif Islam Tentang Strategi Pembelajaran. Kencana: Jakarta.

Purwadi. (2004). Proses Pembentukan Identitas Diri Remaja. Humanitas : Indonesian Psychologycal Journal, 1(1): 43 - 52.

Rahardjo, W. (2007). Kebahagiaan sebagai Suatu Proses Pembelajaran. Jurnal Penelitian Psikologi, $127-137$.

S. N. (2008). Sejarah Pendidikan Islam: menelusuri Jejak Sejarah Pendidikan Era Rasulullah sampai Indonesia. Jakarta: Kencana Preneda Media.

Sasmita, F. E., \& Mariana, N. (2018). Eksplorasi Alquran Surah An-Nisaa dalam Mentransformasi Matematika SD yang Penuh Nilai. Jurnal PGSD 6(4): 526 - 535.

Sudrajat. (2008). Peranan Matematika dalam Ilmu Pengetahuan dan Teknologi. The Power of Mathematics for all Aplications: 1 - 12.

Sugilar, H. (2017). Daya Matematis Mahasiswa Program Studi Matematika. Jurnal Nasional Pendidikan Matematika, 97 - 108.

Suwangsih, Erna dan Tiurlina. (2006). Model Pembelajaran Matematika. Cet.I. Bandung: UPI Press.

Syahrir. (2010). Metodologi Pembelajaran Matematika. Yogyakarta: Naufal Pustaka.

W. S. (2000). Identitas dan ciri khas pendidikan Kristen di Indonesia antara konseptual dan operasional. Jakarta: BPK Gunung Mulia.

Yulianti, R. T. (2002). Riba Dalam Perspektif Ekonomi Islam. Millah, 2: 51 - 70.

Zainuddin. (2008). Paradigma Pendidikan Terpadu. Malang: UIN Press. 